\title{
SURGICAL TREATMENT OF OTOSCLEROSIS: EXPANDING INDICATIONS AND NEW RECOMMENDATIONS
}

\author{
Henryk Skarzynski ${ }^{1,2,3,4}$ \\ ${ }^{1}$ Oto-Rhino-Laryngology Surgery Clinic, Institute of Physiology and Pathology of \\ Hearing, Warsaw/Kajetany, Poland \\ ${ }^{2}$ International Center of Hearing and Speech "Medincus", Warsaw/Kajetany, Poland \\ ${ }^{3}$ Cochlear Center, Warsaw, Poland \\ ${ }^{4}$ Central Clinical Hospital, Medical University of Warsaw, Poland
}

Although many years have passed since the first reports of surgical treatment for otosclerosis in adults were published (1-5), the first reports of treatment of children are much more recent and still very sparse (6-10).

Stapes surgery still faces new challenges. Over many years surgical approaches have evolved, and new materials for making prostheses have become available. Invariably, however, the basis for continued progress in stapes surgery has been improved hearing results from an ever-growing material. This has allowed widening of indications, based on the achievements of many pioneers (11-16). With their surgical experience and their growing base of collected material, they have been able to achieve significant milestones. In Poland, the pioneers of the field, beginning in the 1930s and continuing after the 2 nd World War, were Prof. Jan Miodoński and Prof. Zbigniew Bochenek.

My own personal experience in the surgical treatment of otosclerosis extends over 35 years. The present 4 th International Symposium on Otosclerosis and Stapes Surgery is the perfect occasion to summarize this experience. Over the 35 years I have performed 23,457 stapedectomies and stapedotomies, restapedotomies, or stapedotomy revision surgeries. In the first 10 years it involved between 20 and 100 ear procedures per year, then about 500 ears per year, and in the last 15 years more than 1000 ear surgeries each year. I have compared my experience in personal contacts with otosurgical authorities such as W. House, J.M. Sterkers, E. Offeciers, J. Helms, M. Tos, and U. Fish. This has enabled me to devise my own solutions in daily clinical practice. First, after 5 years of experience, I departed from the usual stapedectomies and started doing stapedotomies. Reducing the invasiveness of stapes interventions has been the basis for expanding the original indications. Having performed surgeries for 30 years in patients younger than 18 , and for 27 years in children younger than 10 , I have seen new possibilities. The youngest boy I have operated on for otosclerosis is 5 years and 1 month of age (17). The total number of ears operated on for otosclerosis in children and youths below 18 years old is 276 . Additionally, there are 82 ears operated on in the same age group due to congenital stapes ankylosis and congenital ear malformations with immobilization of one or more ossicles.

The next widening of the indications for stapes surgery involved operating on the only hearing ear. The number of such surgeries which I have performed over the last
25 years is 427 adult ears. In the same period I have performed stapedotomy in 576 cases of chronic otitis media (after first letting it heal). Stapes surgery has also been a part of entire surgical interventions involving ossiculoplasty of the middle ear area. These data are complemented with stapedotomies in 342 cases of advanced tympanosclerosis and in 275 cases with previous iatrogenic damage to the middle ear.

In the period of 35 years I can distinguish four periods in my otosurgical development relating to stapes surgery.

The first 5 years involved procedures in which sometimes the whole (but more often a significant part) of the stapes footplate was removed. For the purposes of ear surgery I had been making a prosthesis manually using a thin tantalum wire with a ball of fat fixed to its end. I always adjusted the length of the prosthesis based on intraoperative measurements. The rate of early failures was minimal, not higher that $1-2 \%$. The ball of fat fitted very well in the opening made in the vestibule antrum and was tailored to the size of the opening, allowing it to be tightly sealed. Hearing improvement at early observation was good, very good, and sometimes spectacular. However, problems would occur after about a year, when in the majority of patients the fat would undergo significant resorption and the connective tissue formed on its surface was insufficient to seal the wire of the prosthesis. The revision procedure in such cases involved additional packing of the stapes end with a clot of venous blood. The most common motivation for revision was the reappearance of the air-bone gap, caused by adhesions at the end of the wire prosthesis shifting it beyond the window. The results were slightly better, but only if in the early postoperative period the fully exposed oval window was also covered with a fragment of venous wall before placing against it the tantalum wire prosthesis (made as before).

The second period of my otosurgical experience related to stapedotomies, which I have been performing for 30 years. At that time, a calibrated opening was made in the stapes footplate using a manual or electric drill and a $0.6 \mathrm{~mm}$ diamond burr. For almost 10 years during that period I used a Teflon prosthesis with a platinum clasp which had a piston $0.6 \mathrm{~mm}$ in diameter and not more than $2 \mathrm{~mm}$ long. The piston was sealed with a venous blood clot which gave improved hearing stability for up to 3 or 5 years. Problems would arise when the air-bone gap was not fully closed due 
to progressive immobilization of the stapes. It was usually related to regrowth of bony tissue around the piston, or its immobilization from strong connective tissue adhering to it. If gradual reduction of the opening caused the piston to be dislodged, the platinum clasp could damage or destroy the end of the long process of the incus.

The third period of stapes surgery was connected to the realization that a family of prostheses with a Teflon piston $4 \mathrm{~mm}$ long and $0.6,0.42$, or $0.37 \mathrm{~mm}$ in diameter could be used. This enabled better modelling of the prosthesis, especially in cases of a narrow oval window niche or an overhanging canal or, often, an overhanging prolapsed facial nerve. The longer and thinner piston, and the thinner piece of platinum (in the shape of a very narrow tape or wire), allows the prosthesis to be modelled around the facial nerve canal and beside the nerve in the narrow window niche (or, in cases of advanced otosclerosis, in a narrow canal made in the significantly thickened footplate). The collected results of treatment of different forms of otosclerosis, both early and advanced, were better than all previous results. Failure or revision surgery was necessary in only about $0.5 \%$ of cases, most often due to immobilization of the piston in the thickened footplate.

The most recent period in my stapes surgery practice is related to the use of titanium prostheses of the Kurz Skarzynski type with a piston diameter of $0.5 \mathrm{~mm}$ and length of $4 \mathrm{~mm}$. This allows optimal placement of the piston in the $0.6 \mathrm{~mm}$ opening and at the same time very good sealing with a small fragment of venous blood clot. The longer and thinner piston can be modelled either for a narrow niche or overhanging facial nerve; it also has good fixation on the stump of a partially destroyed long process of the incus after previous surgeries.
My 35 years of experience allows me to recommend this approach to otosurgery as safe in the following cases:

a) practically all forms of otosclerosis;

b) in cases of otosclerosis in children and adolescents who have the same conditions as in adults;

c) in cases of bilateral and well as unilateral otosclerosis in the only hearing, or better hearing, ear.

The above recommendations remove any doubts about the application of stapedotomy to cases of progressive hearing loss and tinnitus in small children, or in cases involving the only hearing ear, where refraining from intervention does not improve the patient's safety and where conventional hearing aids give only short-lasting benefit. The minimal number of unsatisfactory results in recent years, on the level of single cases per thousand, makes stapedotomy a procedure to be recommended in any patient with otosclerosis. Stapedotomy may be aimed at achieving fully efficient hearing, or at preparing the ear for complementary hearing amplification. The complementary amplification may involve conventional hearing aids, middle ear implants of the Vibrant Soundbridge type, or direct stimulation of the inner ear with a CODACS type implant (18-20).

Summarizing, I think that the stapedotomy procedure performed through the external auditory canal using a minimally invasive approach to the inner ear, application of a titanium prosthesis with a longer piston, and eventual complementation with a conventional hearing aid, middle ear implant, or CODACS implant - is the optimal approach to stapes surgery. The procedure allows for optimal closure of the air-bone gap and consequently ensures the most stable hearing effects.

\section{References:}

1. Tange RA. The history of otosclerosis treatment: a survey of more than a century's search for the best treatment of the disease. Kugler, 2014.

2. Hall IS. Surgical treatment of otosclerosis. Proc R Soc Med, 1944; 37(12): 737-43.

3. Shambaugh GE. Fenestration operation: a clinical study of the performance of its results. Q Bull Northwest Univ Med Sch, 1945; 19(4): 259-64.

4. Shambaugh GE, Juers AL. Chronic progressive deafness, including otosclerosis and diseases of the inner ear; review of the literature for 1944 and 1945. Arch Otolaryngol, 1947; 45(6): 697-717.

5. De Weese DD. Fenestration for otosclerosis; technic and results in 11 cases. Bull Portland Clin, 1947; 1(1): 3-8.

6. Neilan RE, Zhang RW, Roland PS, Isaacson B, Lee KH, Walter Kutz J. Pediatric stapedectomy: does cause of fixation affect outcomes? Int J Pediatr Otorhinolaryngol, 2013; 77(7): 1099-102.

7. Guild SR. Histologic otosclerosis. Ann Otol Rhinol Laryngol, 1944; 53(1045): 246-266.

8. Raveh E, Hu W, Papsin BC, Forte V. Congenital conductive hearing loss. J Laryngol Otol, 2002; 116(2): 92-6.

9. Syms CA, De la Cruz A. Pediatric otology. Otolaryngol Clin North Am, 1996; 29(3): 407-20.

10. Tringali S, Pouget J-F, Bertholon P, Dubreuil C, Martin C. Value of temporal bone density measurements in otosclerosis patients with normal-appearing computed tomographic scan. Ann Otol Rhinol Laryngol, 2007; 116(3): 195-8.

11. Barbara M, Monini S, Seta E de, Filipo R. Early hearing evaluation after microdrill stapedotomy. Clin Otolaryngol Allied Sci, 1994; 19(1): 9-12.

12. Van Rompaey V, Yung M, Claes J, Häusler R, Martin C, Somers $\mathrm{T}$ et al. Prospective effectiveness of stapes surgery for otosclerosis in a multicenter audit setting: feasibility of the Common Otology Database as a benchmark database. Otol Neurotol, 2009; 30(8): 1101-10.

13. Somers T, Govaerts P, Marquet T, Offeciers E. Statistical analysis of otosclerosis surgery performed by Jean Marquet. Ann Otol Rhinol Laryngol, 1994; 103(12): 945-51.

14. Nazarian R, McElveen JT, Eshraghi AA. History of otosclerosis and stapes surgery. Otolaryngol Clin North Am, 2018; 51(2): 275-90.

15. Shin YJ, Fraysse B, Deguine O, Cognard C, Charlet JP, Sévely A. Sensorineural hearing loss and otosclerosis: a clinical and radiologic survey of 437 cases. Acta Otolaryngol (Stockh), 2001; 121(2): 200-4.

16. Nguyen Y, Bernardeschi D, Sterkers O. Potential of robot-based surgery for otosclerosis surgery. Otolaryngol Clin North Am, 2018; 51(2): 475-85. 
17. Skarżyński H, Boruta M, Dziendziel B, Rajchel JJ, Skarżyński $\mathrm{PH}$. Surgical treatment of a 5-year-old boy with otosclerosis: a case study. J Hear Sci, 2018; 7(3).

18. Skarzynski H, Olszewski L, Skarzynski PH, Lorens A, Piotrowska A, Porowski M i wsp. Direct round window stimulation with the Med-El Vibrant Soundbridge: 5 years of experience using a technique without interposed fascia. Eur Arch Otorhinolaryngol, 2014; 271(3): 477-82.
19. Skarżyński H, Porowski M, Mrówka M, Barylyak R, Skarżyński PH. Zastosowanie implantu ucha środkowego Vibrant Soundbridge $\mathrm{w}$ połączeniu $\mathrm{z}$ couplerem typu SP w przypadku przewlekłego zarostowego zapalenia ucha: opis przypadku. Now Audiofonol, 2015; 4(1): 75-8.

20. Skarżyński H, Szkiełkowska A, Olszewski Ł, Mrówka M, Porowski M, Fabijańska A i wsp. Program stosowania implantów ucha środkowego i implantów zakotwiczonych w kości skroniowej na przewodnictwo kostne w leczeniu zaburzeń słuchu. Now Audiofonol, 2015; 4(1): 9-23. 
